\title{
Role of Learning Approach in Determining Learning Outcome During Active and Passive Learning Sessions in Pharmacology
}

\author{
Vimala Ananthy ${ }^{1, *}$, Suresh Narayanan ${ }^{2}$, Arthi Asokan ${ }^{3}$ \\ 1'Department of Pharmacology, Mahatma Gandhi Medical College and Research Institute, Puducherry, INDIA. \\ ${ }^{2}$ Department of Anatomy, Sri Manakula Vinayagar Medical College and Hospital, Puducherry, INDIA. \\ ${ }^{3}$ Department of Anesthesiology, Sri Venketeshwara Medical College and Research Institute, Puducherry, INDIA.
}

\begin{abstract}
Objectives: The objective of the study is to estimate the difference in knowledge gain between the students of varied learning approaches during didactic lectures and concept mapping lectures. Materials and Methods: The study participants included 118 secondyear medical undergraduate students. The learning approaches of the participants were assessed using the ASSIST questionnaire on a 5-point Likert-type scale. Two lectures in pharmacology subject were taken using the concept mapping technique and two lectures were taken in didactic format with an equal difficulty level. The students' prior knowledge was assessed using 40 MCQ's that were given 4 days before the commencement of the lectures with $10 \mathrm{MCQs}$ from each topic. The same questions were given to the students 3 weeks after the completion of the each lecture. Results: The score improvement of the three categories of learners was significantly higher for concept mapping session when compared to the didactic lectures. There was no significant difference in the score improvement between the surface, strategic and deep learners in both didactic and concept mapping sessions. Conclusion: The learning approach did not influence the long-term knowledge retention following didactic and concept mapping sessions. Learners study strategy and the mode of assessment could play a role in determining the knowledge outcome.
\end{abstract}

Keywords: Learning approach, Deep learners, Surface learners, Strategic learners, Learning outcome.

\section{INTRODUCTION}

In pharmacology teaching, the medical students are exposed to the classification of drugs, mechanism of action, indications and its adverse effects. This acquired knowledge is essential for the safe and rationale prescription of drug usage during clinical practice. ${ }^{1}$ However, studies have reported that the majority of the final year students and interns are not adequately prepared for the safe prescription of drugs. ${ }^{2,3}$ This indicates that either the medical students did not acquire the required theoretical knowledge or they lack the ability to apply the knowledge in routine clinical practice. Hence, there is a need for effective teaching strategies that focuses on engaging the learner on relevance and application of the learned materials.

The current teaching modalities in Indian medical colleges include a combination of didactic lectures with practical session. But the passive mode of teaching creates a monotonous teaching environment with limited scope of active learning thereby resulting in rote learning. ${ }^{4,5}$ Hence educators have resorted to active strategies like case-based learning and concept mapping to promote meaningful learning in a large group setting. ${ }^{6,7}$ The concept mapping technique is a graphical instructional strategy that enables the learner to organize and represent the learned knowledge in a meaningful
Submission Date: 19-02-2021; Revision Date: 13-04-2021; Accepted Date: 26-05-2021

DOI: 10.5530/ijper.55.2s.109 Correspondence: Dr.A. Vimala Ananthy Assistant Professor Department of Pharmacology, Mahatma Gandhi Medical College and Research Institute, Puducherry - 607402, India

Phone: +91-0413-2615450, Fax: $+91-0413-2615457$ Email -drvimala90@gmail. com

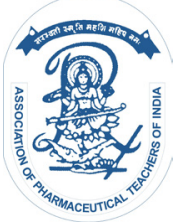

www.ijper.org 
manner. ${ }^{8,9} \quad$ Incorporating concept mapping as an instructional method can promote better understanding and retention of the subject knowledge than traditionaldidacticlectures. ${ }^{10}$ However, in a classroom of students with varied learning approaches, it is unclear which subset of students gets benefited from the concept mapping teaching strategy. The learning approach refers to the behavioral and intellectual response elicited by the learner during the learning process. ${ }^{11}$ The Approaches and Study Skills Inventory for Students (ASSIST) instrument is used to categorize students into superficial, strategic, and deep learners. The surface approach involves investing little time in acquiring meaningful knowledge and more focused on memorization. Students adopting a strategic approach organize their work efficiently but still have a fragmented understanding of the subject content. A student with a deep approach analyzes the newly acquired information for a meaningful interpretation. ${ }^{12}$ Previous studies have documented higher academic outcomes among deep and strategic learners when compared to surface learners. ${ }^{13-15}$ Another study has documented a weak but statistically significant association between deep learners and the self-reported use of a pre-prepared concept map. ${ }^{16}$ However, the role of the students learning approach in determining the knowledge outcome during an active learning strategy has not been investigated.

The present study aims to determine whether the students learning approach has any influence over long-term knowledge retention during a didactic session and concept mapping session. This study could provide insight for educators on the learner characteristics which determine the long-term retention of knowledge. The objective of the study was to estimate the difference in knowledge gain between the students of superficial, strategic and deep approach in didactic lectures and concept mapping lectures.

\section{MATERIALS AND METHODS}

This was a quasi-experimental study with a single group pre-test and post-test design. The study was approved by the institutional research and ethics committee (Approval certificate No: MGMCRI/IRC/04/2020/ $\mathrm{XX} / \mathrm{IHEC} / 139)$. The study group included secondyear MBBS students from a private medical college in Puducherry. All the students were informed about the study procedure and were sensitized regarding the concept mapping method of teaching before the commencement of the study. Written informed consent was obtained from the participants before data collection and subject confidentiality was maintained throughout the study.

The learning approaches of the participants were assessed using the ASSIST questionnaire on a 5-point Likert-type scale. The questionnaire had 52 items that identified the learner's approach to studying (surface approach - 6 items, strategic approach - 20 items, and the deep approach - 16 items). A hard copy of the questionnaire was given to the participants 2 weeks before the commencement of the lectures and was asked to fill and submit. Based on the scores, the students were classified into a surface, deep and strategic learners.

The study participants attended the lectures as a single group. A total of four lectures which required conceptual understanding with equal difficulty were selected by two senior faculties. The lectures were taken over a period of 2 weeks by the first author to avoid variation in the teaching style. The sequence of the lectures was pharmacotherapy of leishmaniasis (CM session), pharmacotherapy of vaginitis (didactic session), pharmacology of inhalational agents (didactic session) and pharmacology of inducing agents (CM session). During CM sessions, the classification of drugs, mechanism of action, indications, and side effects were depicted graphically and the learners were requested to draw and label diagrams progressively throughout the lecture. During the didactic sessions, the subject content was provided in conventional textual format and the students were encouraged to take notes. The knowledge outcome was assessed using multiple-choice questions (MCQ's) at the application level of bloom's taxonomy using scenariobased questions. They were validated before the study with the help of a medical education expert and a pharmacologist. All the 40 MCQ's were given 4 days before the commencement of the lectures which included $10 \mathrm{MCQ}$ from each topic. The same questions were given to the students 3 weeks after the completion of the each lecture to assess the long-term retention of knowledge. The MCQ's were chosen as the mode of assessment because of its feasibility and objectivity to simultaneously assess a large number of students.

The normalized learning gain (NLG) for an individual student was calculated using the formula NLG = (post-test score - pre-test score)/(maximum score pre-test score). NLG of $<0.30$ indicates low learning gain, $0.30 \leq$ or $\leq 0.70$ indicates medium learning gain and $>0.70$ denotes higher learning gain. ${ }^{17}$ The normalization reduces the influence of the pre-test score of the learner over the score improvement and permits the comparison between the groups. ${ }^{17}$ The mean and standard deviation of the knowledge gain for different 
types of learners was calculated. The Shapiro-Wilk test for normality was performed and they showed a nonnormal distribution. The knowledge gain difference between the lecture and concept mapping session was estimated using the Wilcoxon signed-rank test. The difference in knowledge gain between the three categories of learners was estimated using the Kruskal Wallis test. The statistical analysis was done using SPSS version 23.0 and a $p$-value less than 0.05 was considered statistically significant.

\section{RESULTS}

Out of 118 students, a total of 100 students (40 males and 60 females) who had completed both the ASSIST questionnaire and MCQ's were included for analysis. The frequency of the different types of learners was surface $8(8 \%)$, deep $58(58 \%)$, and strategic learners 34 (34\%). The NLG score improvement was significantly higher for the CM session when compared to the didactic lecture session (Table 1). There was no significant difference in the NLG score between the surfaces, strategic and deep learners in both didactic and concept mapping sessions (Table 2).

\section{DISCUSSION}

In the present study, the authors endeavored to promote active learning during the pharmacology lectures by introducing a concept mapping teaching strategy. This intervention was implemented to promote meaningful learning through graphical linking of the concepts. The knowledge retention was significantly higher for the concept mapping lectures than the didactic lectures. However, the students learning approach did not influence knowledge retention in both didactic and concept mapping sessions.

Samarakoon et al. demonstrated that the strategic approach was the predominant learning approach adopted by preclinical, clinical, and post-graduate students. ${ }^{18}$ Chonkar et al. reported that the majority of medical students in clinical background adopted the

Table 1: Normalized knowledge gain score for concept mapping lectures and didactic lectures

\begin{tabular}{|c|c|c|c|}
\hline \multirow{2}{*}{ Learning approach } & \multicolumn{2}{|c|}{ Normalized knowledge gain score } & \multirow{2}{*}{$\begin{array}{c}\text { Wilcoxon signed rank test } \\
(p \text { value })\end{array}$} \\
\cline { 2 - 4 } & $\begin{array}{c}\text { Lecture using concept mapping } \\
\text { (mean } \pm \text { SD) }\end{array}$ & $0.04 \pm 0.08$ & $0.02 *$ \\
\hline $\begin{array}{c}\text { Surface } \\
(\boldsymbol{n}=8)\end{array}$ & $0.26 \pm 0.18$ & $0.08 \pm 0.25$ & $<0.001^{*}$ \\
\hline $\begin{array}{c}\text { Deep } \\
(\boldsymbol{n}=58)\end{array}$ & $0.28 \pm 0.18$ & $0.12 \pm 0.27$ & $0.001^{*}$ \\
\hline $\begin{array}{c}\text { Strategic } \\
(\boldsymbol{n}=\mathbf{3 4 )}\end{array}$ & $0.33 \pm 0.22$ & & \\
\hline
\end{tabular}

SD - Standard deviation

* $p$ value $<0.05$ indicates a significant difference

\begin{tabular}{|c|c|c|c|}
\hline Teaching sessions & Learning approach & $\begin{array}{l}\text { Normalized knowledge gain } \\
\text { (mean } \pm \text { SD) }\end{array}$ & $\begin{array}{l}\text { Kruskal Wallis test } \\
\text { ( } p \text { value) }\end{array}$ \\
\hline \multirow{3}{*}{ Didactic lectures } & $\begin{array}{l}\text { Surface } \\
(n=8)\end{array}$ & $0.04 \pm 0.08$ & \multirow{3}{*}{0.429} \\
\hline & $\begin{array}{l}\text { Deep } \\
(n=58)\end{array}$ & $0.08 \pm 0.25$ & \\
\hline & $\begin{array}{l}\text { Strategic } \\
(n=34)\end{array}$ & $0.12 \pm 0.27$ & \\
\hline \multirow{3}{*}{$\begin{array}{l}\text { Lectures with concept } \\
\text { mapping }\end{array}$} & $\begin{array}{l}\text { Surface } \\
(n=8)\end{array}$ & $0.26 \pm 0.18$ & \multirow{3}{*}{0.418} \\
\hline & $\begin{array}{l}\text { Deep } \\
(n=58)\end{array}$ & $0.28 \pm 0.18$ & \\
\hline & $\begin{array}{c}\text { Strategic } \\
(n=34)\end{array}$ & $0.33 \pm 0.22$ & \\
\hline
\end{tabular}

SD - Standard deviation

* $p$ value $<0.05$ indicates a significant difference 
strategic approach (50.8\%), followed by deep (40.3\%) and superficial approach $(8.8 \%) .{ }^{19}$ Our findings are consistent with the abovementioned studies where there was a predominance of deep and strategic approach among the learners. The observed trend reflects the nature of the teaching strategies and the learners' adaptation towards an integrated curriculum. ${ }^{18,20}$ However, it is to be remembered that the learning approach of a student is a dynamic phenomenon and tend to change as the course progress and does not echo the personal characteristic of the learner. ${ }^{21}$

Bala et al. used concept mapping to teach general awareness and pharmacotherapy of acquired immune deficiency syndrome (AIDS) among second-year medical students. The authors reported significant improvement in the multiple-choice question and problem-based question scores after indulging the learners in preprepared concept mapping sessions. ${ }^{7}$ Gonzalez et al. conducted a randomized controlled study among students studying cardiovascular physiology to analyze the effectiveness of concept mapping. The authors demonstrated significantly higherscores by the concept mappinggroupin the problem-solving format but not in the multiple-choice format. ${ }^{22}$ In the present study, scenario-based questions were utilized to assess whether the learned knowledge was applied by medical students. The knowledge gain was significantly higher in concept mapping lectures among all the three categories of learning approaches in multiple-choice format. This indicates that active organization and linking of concepts has fostered the better application of the learned knowledge among all the type of learners.

Bonsaken et al. analyzed the learning approach of undergraduate occupational therapy students and demonstrated a significant association between the deep approach subscale of "seeking meaning" with a highergrade point average calculated at the end of the course. ${ }^{13}$ The present study varies from the abovementioned study in comparing the test score of a selected few teaching session to establish a clear influence of the learning approach over the knowledge gain obtained through the intervention. Since the concept mapping strategy promotes a deeper understanding of the subject ${ }^{8,9}$, students with a deep approach were expected to score better than surface learners. Moreover, a study has documented a weak but significant association between deep learners and the self-reported use of a preprepared concept map. ${ }^{16}$ In the present study, there was a lack of significant difference in knowledge retention between students with varied learning approaches. This indicates that the academic performance measured at the end of the course reflects the learning style of the learner but not in a selected few teaching session. The possible explanation for the lack of difference could be the smaller size of the superficial learner group, restriction of the study to a limited number of teaching sessions, or the lack of congruence between the studying approach and the preferred methodology of assessment. ${ }^{23,24}$

Teaching strategies like concept mapping focused on promoting a deeper understanding of the subject not only benefits the deep learners and strategic learners but also superficial learners. Apart from the learning approach, factors like interest in the subject content, studying strategies (time spent on studying and use of resources), and the mode of assessment might have also influenced the learners' retention of knowledge. ${ }^{25-27}$ The strengths of the study include a large sample size, uniformity in the conduct of the teaching sessions by the same lecturer, and the measurement of long-term retention rather than the immediate acquisition of knowledge. The normalized learning gain utilized in the study is a better indicator to assess the knowledge gain than the post-test scores. The key limitations include, restriction of the students belonging to a single institution, a limited number of teaching sessions, and the intrusion of factors outside the study design which might have influenced the learners' knowledge retention. These factors should be considered before generalizing the findings for wider interpretation.

Concept mapping is a feasible active learning strategy to promote a deeper understanding of the subject content among students with the varied learning approach. ${ }^{28}$ Inculcating such a technique might also enable the learner to develop similar studying strategies during routine learning. This work adds to the growing area of research that supports the vital role of instructional design in determining the academic outcome. However, to establish a clear correlation between the learning approach and the outcome following an intervention, a randomized control design could be more suitable. Future research can focus on the influence of the learning approach on students' performance in the flipped classroom or different modalities of assessment.

\section{ACKNOWLEDGEMENT}

We thank all the medical students who accepted to participate in the study and the institution for providing the technical support. 


\section{CONFLICT OF INTEREST}

The authors declare that there is no conflict of interest.

\section{ABBREVIATIONS}

ASSIST: Approaches and Study Skills Inventory for Students; MCQs: Multiple Choice Questions; NLG: Normalised learning gain; CM: Concept mapping.

\section{REFERENCES}

1. Chaturvedi VP, Mathur AG, Anand AC. Rational drug use - As common as common sense? Med J Armed Forces India. 2012;68(3):206-8. doi: 10.1016/j.mjafi.2012.04.002, PMID 24532868.Coombes ID, Mitchell CA, Stowasser DA. Safe medication practice: attitudes of medical students about to begin their intern year. Med Educ. 2008;42(4):427-31. doi: 10.1111/j.13652923.2008.03029.x, PMID 18338996.

2. Heaton A, Webb DJ, Maxwell SR. Undergraduate preparation for prescribing: the views of 2413 UK medical students and recent graduates. $\mathrm{Br} \mathrm{J}$ Clin Pharmacol. 2008;66(1):128-34. doi: 10.1111/j.1365-2125.2008.03197.x, PMID 18492128.

3. Badyal DK. Pharmacology education in India: challenges ahead. Indian J Pharmacol. 2016;48(Suppl 1):S3-4. doi: 10.4103/0253-7613.193327, PMID 28031598.Badyal DK. Evolution of pharmacology education in India: past and future. Indian J Pharmacol. 2018;50(4):159-68. doi: 10.4103/ijp.IJP_239_18, PMID 30505051.Kaur G, Rehncy J, Kahal KS, et al. Case-based learning as an effective tool in teaching pharmacology to undergraduate medical students in a large group setting. J Med Educ Curric Dev. 2020;7:2382120520920640. doi: 10.1177/2382120520920640, PMID 32435693.Bala S, Dhasmana DC, Kalra J, Kohli S, Sharma T. Role of concept map in teaching general awareness and pharmacotherapy of HIVIAIDS among second professional medical students. Indian J Pharmacol. 2016;48(Suppl 1):S37-40. doi: 10.4103/0253-7613.193323, PMID 28031606.

4. Pudelko B, Young M, Vincent-Lamarre P, Charlin B. Mapping as a learning strategy in health professions education: a critical analysis. Med Educ. 2012;46(12):1215-25. doi: 10.1111/medu.12032, PMID 23171264.

5. Daley BJ, Torre DM. Concept maps in medical education: an analytical literature review. Med Educ. 2010;44(5):440-8. doi: 10.1111/j.13652923.2010.03628.x, PMID 20374475.

6. Surapaneni KM, Tekian A. Concept mapping enhances learning of biochemistry. Med Educ Online. 2013;18(1):1-4. doi: 10.3402/meo. v18i0.20157. Entwistle N, McCune V. The conceptual bases of study strategy inventories. Educ Psychol Rev. 2004;16(4):325-45. doi: 10.1007/s10648-0040003-0

7. Byrne M, Flood B, Willis P. Validation of the approaches and study skills inventory for students (assist) using accounting students in the USA and Ireland: a research note. Accounting Education: an International Journal 2004;13:449-59.
8. Bonsaksen T, Brown T, Lim HB, Fong K. Approaches to studying predict academic performance in undergraduate occupational therapy students: a cross-cultural study. BMC Med Educ. 2017;17(1):76. doi: 10.1186/s12909017-0914-3, PMID 28464809.

9. Wickramasinghe DP, Samarasekera DN. Factors influencing the approaches to studying of preclinical and clinical students and postgraduate trainees. BMC Med Educ. 2011;11:22. doi: 10.1186/1472-6920-11-22, PMID 21599886

10. Ward PJ. Influence of study approaches on academic outcomes during pre-clinical medical education. Med Teach. 2011;33(12):e651-62. doi: 10.3109/0142159X.2011.610843, PMID 22225447.

11. Laight DW. Attitudes to concept maps as a teaching/learning activity in undergraduate health professional education: influence of preferred approach to learning. Med Teach. 2006;28(2):e64-7. doi: 10.1080/01421590600617574, PMID 16707287.

12. Hake RR. Interactive-engagement versus traditional methods: A six-thousandstudent survey of mechanics test data for introductory physics courses. Am J Phys. 1998;66(1):64-74. doi: 10.1119/1.18809.

13. Samarakoon L, Fernando T, Rodrigo C. Learning styles and approaches to learning among medical undergraduates and postgraduates. BMC Med Educ. 2013;13:42. doi: 10.1186/1472-6920-13-42, PMID 23521845.

14. Chonkar SP, Ha TC, Chu SSH, Ng AX, Lim MLS, Ee TX, Ng MJ, Tan KH The predominant learning approaches of medical students. BMC Med Educ. 2018;18(1):17. doi: 10.1186/s12909-018-1122-5, PMID 29347934.

15. Nijhuis JFH, Segers MSR, Gijselaers WH. Influence of redesigning a learning environment on student perceptions and learning strategies. Learning Environ Res. 2005;8(1):67-93. doi: 10.1007/s10984-005-7950-3.

16. Reid WA, Evans P, Duvall E. Medical students' approaches to learning over a full degree programme. Med Educ Online. 2012;17:1-7. doi: 10.3402/meo. v17i0.17205, PMID 22927717.

17. González HL, Palencia AP, Umaña LA, Galindo L, Villafrade M LA. Mediated learning experience and concept maps: a pedagogical tool for achieving meaningful learning in medical physiology students. Adv Physiol Educ. 2008;32(4):312-6. doi: 10.1152/advan.00021.2007, PMID 19047509.

18. Chen TC, Hu MH. Influence of course design on learning approaches and academic performance in physical therapy students. Procedia Soc Behav Sci. 2013;93:97-101. doi: 10.1016/j.sbspro.2013.09.158.Baeten M, Dochy F, Struyven K. Students' approaches to learning and assessment preferences in a portfolio-based learning environment. Instr Sci. 2008;36(5-6):359-74. doi: 10.1007/s11251-008-9060-y.Eleazer CD, Scopa Kelso R. Influence of study approaches and course design on academic success in the undergraduate anatomy laboratory. Anat Sci Educ. 2018;11(5):496-509. doi: 10.1002/ ase.1766, PMID 29314722.

19. Van der Vleuten CP, Schuwirth LW. Assessing professional competence: from methods to programmes. Med Educ. 2005;39(3):309-17. doi: 10.1111/j.13652929.2005.02094.x, PMID 15733167.

20. Diseth A, Pallesen S, Brunborg GS, Larsen S. Academic achievement among first semester undergraduate psychology students: the role of course experience, effort, motives and learning strategies. High Educ. 2010;59(3):335-52. doi: 10.1007/s10734-009-9251-8.

21. Torre DM, Durning SJ, Daley BJ. Twelve tips for teaching with concept maps in medical education. Med Teach. 2013;35(3):201-8. doi: 10.3109/0142159X.2013.759644, PMID 23464896 
PICTORIAL ABSTRACT
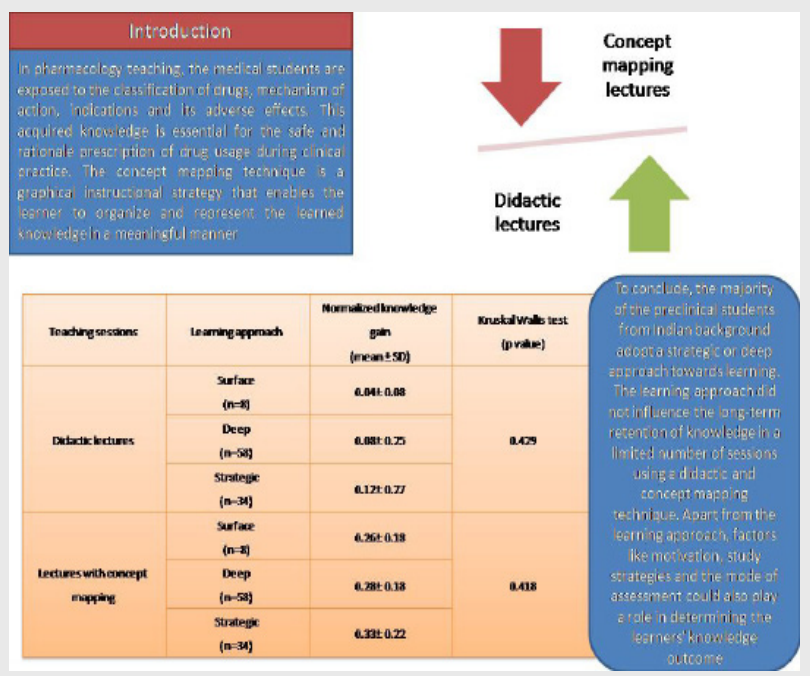

\section{SUMMARY}

To summarise, the majority of preclinical students from India take a strategic or deep approach. In a small number of sessions employing a didactic and concept mapping strategy, the learning strategy had no effect on long-term information retention. Motivation, study strategies, and the manner of evaluation, in addition to the learning technique, may all play a role in deciding the learners' knowledge output.

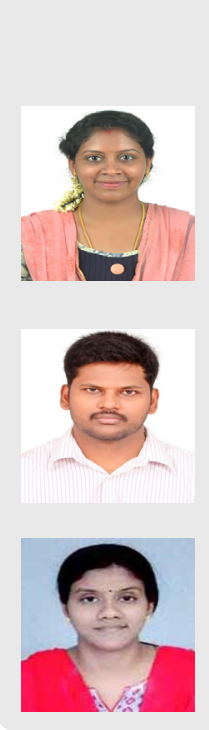

\section{About Authors}

Dr. Vimala Ananthy has obtained her MBBS degree from Sri Venketeshwara Medical College and Research Institute and MD Pharmacology from JIPMER. Her field of interest is medical education, pharmacogenomics and drug utilization studies. She has authored four research papers in national and international journal.

Dr. Suresh Narayanan has obtained his MBBS degree from Pondicherry Institute of medical science and MD Anatomy from St. John medical college, Bangalore. His area of research is medical education and interested in innovative teaching methods. He has authored 14 research papers in international journals

Dr. Arthi Asokan has obtained her MBBS degree from Vinayaka Missions, Karaikal and MD Anesthesia from Aligarh Muslim University. She pursued her fellowship in neuro-anesthesia from Christian medical college, Vellore. Her area of interest is in obstetric anesthesia, medical education and pain management. She has authored 3 research papers in national journals.

Cite this article: Ananthy V, Narayanan S, Asokan A. Role of learning approach in determining learning outcome during active and passive learning sessions in pharmacology. Indian $\mathrm{J}$ of Pharmaceutical Education and Research. $2021 ; 55(2 s): s 379-s 384$. 